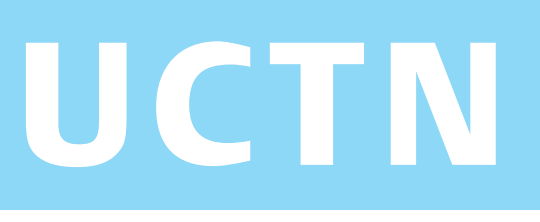

\title{
Endoscopy-Assisted Wireless Intragastric pH Measurement
}

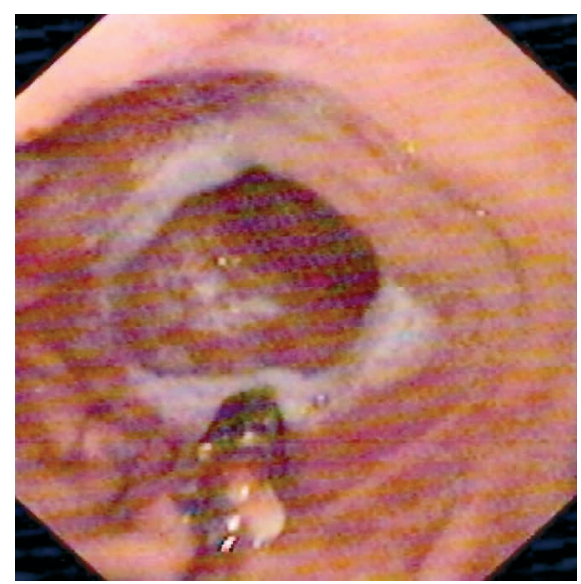

Figure 1 The wireless $\mathrm{pH}$ capsule attached to the gastric mucosa.

Intragastric $\mathrm{pH}$ monitoring is an important tool for assessing the pharmacodynamic profiles of antisecretory agents [1].

Ambulatory 24-hour intragastric $\mathrm{pH}$ monitoring is usually done by means of an antimony or glass electrode that is placed transnasally. Limitations of catheter-based $\mathrm{pH}$ monitoring include discomfort, inconvenience, and interference with normal activity for patients. In addition, precise placement of the $\mathrm{pH}$ electrode is crucial for the method, with manometry being required to locate the position of the lower esophageal sphincter [2].

The Medtronic Bravo pH Monitoring System (Medtronic, Vadodara, Gujarat) is a new US Food and Drug Administration (FDA) class 1-approved catheter-free esophageal $\mathrm{pH}$ monitoring system that involves the attachment of a radio telemetry capsule to the mucosal wall [3]. There are no published data on the use of the new Bravo system for intragastric $\mathrm{pH}$ monitoring. We hereby report on the safety, performance, and tolerability of this wireless recording system for intragastric $\mathrm{pH}$ when the capsule is implanted under endoscopic guidance.

A 26-year-old asymptomatic healthy male volunteer was enrolled. The capsule delivery system was passed orally under

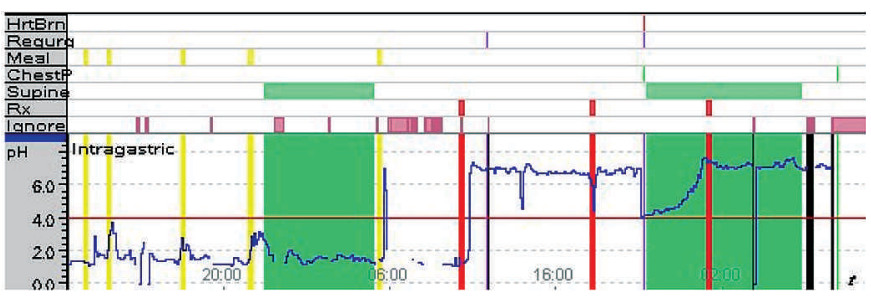

Figure 2 Intragastric $\mathrm{pH}$ tracing over 48 hours.

endoscopic guidance, with the patient in the left lateral decubitus position. The gastroesophageal junction was first located by endoscopy and then the delivery system was advanced under direct vision so that the $\mathrm{pH}$ electrode was at the greater curvature about $10 \mathrm{~cm}$ below the squamocolumnar junction. The capsule was then secured to the gastric mucosa following the standard instructions in the user manual (Figure $\mathbf{1}$ ).

A 24-hr baseline $\mathrm{pH}$ was recorded as the volunteer continued his regular activities. He fasted for the next 24 hours and intravenous rabeprazole given according to the study protocol. On completion of recording, the data were uploaded to a computer via datalink (Medtronic) and a summary of the $\mathrm{pH}$ data was generated (Figure $\mathbf{2}$ ).

This endoscopy-assisted wireless ambulatory $\mathrm{pH}$ recording system appears to be a well-tolerated, reliable means of monitoring intragastric $\mathrm{pH}$. The endoscopic visualization ensures uniform and accurate positioning and avoids local trauma during placement. The mucosal attachment of the electrode virtually eliminates the possibility of recording artifacts related to relative movement between the $\mathrm{pH}$ electrode and the mucosa during the monitoring period. This refinement in methodology will permit broader use of intragastric $\mathrm{pH}$ monitoring.

\section{R. Banerjee, S. Lakhtakia, M. Tandon, G. V. Rao, D. N. Reddy \\ Department of Gastroenterology, Asian Institute of Gastroenterology, Hyderabad, India}

\section{References}

${ }^{1}$ Katz PO. Ambulatory intragastric $\mathrm{pH}$ monitoring: clinical laboratory to clinical practice. Rev Gastroenterol Disord 2003; 3 Suppl 4: S3 - S9

${ }^{2}$ Armstrong D, Bair D, James Cet al. Oral esomeprazole vs. intravenous pantoprazole: a comparison of the effect on intragastric $\mathrm{pH}$ in healthy subjects. Aliment Pharmacol Ther 2003; 18: $705-$ 711

${ }^{3}$ Pandolfino JE, Richter JE, Ours Tet al. Ambulatory esophageal $\mathrm{pH}$ monitoring using a wireless system. Am J Gastroenterol 2003; 98: 740-749

\section{Correspondling Author}

\section{N. Reddy, M.D.}

Department of Gastroenterology Asian Institute Of Gastroenterology 6-3-661 Somajiguda Hyderabad 500082 India

Fax: $\quad+91-40-23324255$

E-mail: aigindia@yahoo.co.in 